\title{
Individual Educational Trajectories in Higher Education Institution - Global Challenges for Regions
}

\author{
Galina Parnikova, ${ }^{1, *}$, and Svetlana Antsupova ${ }^{2}$ \\ ${ }^{1}$ North-Eastern Federal University, 677000, Belinskogo Str., 58, Yakutsk, Russia \\ ${ }^{2}$ North-Eastern Federal University, 677000, Kulakovskogo Str., 50, Yakutsk, Russia
}

\begin{abstract}
The need to introduce individualization of education in the universities of Yakutia is dictated by the need to find optimum solutions for preserving human capital in the northern territories, attracting applicants to regional universities and the labor market's need for competitive specialists from the local population. The purpose of the study is to develop innovative approaches to the educational process in regional universities in the context of global challenges. Research methods: analysis and processing of data from an array of theoretical sources and educational practice; modeling. Scientific novelty of the research: a personalityoriented model of education at the university has been built, taking into account the regional specifics and factors affecting the formation of individual educational trajectories of students.
\end{abstract}

\section{Introduction}

The search for reserves of pedagogical science for a qualitative breakthrough in higher education attract the attention of researchers in our country and abroad $[1 ; 2 ; 3 ; 4]$. Yakutia is the largest territorial entity of the Russian Federation, characterized by specific features, both in the content of the main professional educational programs and in the contingent of students [5]. The need to transform the higher education system in the north-east of the country is actualized in the context of the implementation of large-scale national projects in the northern region and the country as a whole.

The target audience of the research is students, whose generation is usually called the centenaries (born in the period since 1995). They live, study, communicate, work without leaving social networks, are committed to digital services and virtual platforms. In this regard, we ask the following questions. How it is better to train the centenial? Can Generations $\mathrm{X}$ and $\mathrm{Y}$ teach successfully while ignoring the characteristics of today's students? How may a university create an educational product that will be in demand among a modern student, parent, or employer?

The universities in the regions are in the most difficult situation: the local labor market is characterized by high competition between local and foreign labor resources. The

\footnotetext{
* Corresponding author: allerigor@yandex.ru
} 
working curricula of university programs do not have sufficient flexibility in relation to the labor market, suffer from a formal approach to the implementation of the practical training of future specialists with a parallel heavy workload of general theoretical disciplines. According to employers, the level of theoretical training of students is assessed relatively high, but the relatively weak practical orientation of graduates does not satisfy them in many respects [6].

\section{Methods and types of the Earth's remote sensing}

The need to introduce individualization of education, to build an individual educational route for a university student in Yakutia is dictated by the need to find optimum solutions for preserving human capital in the northern territories, attracting applicants to regional universities and the need of the labor market for competitive specialists from the local population [7]. The purpose of the study is to develop innovative approaches to building a student's educational trajectory as a tool that increases the attractiveness of a university in the region. Research object: professional training of qualified personnel in Yakutia. The subject of research: the technology of implementing the individual educational trajectory of students, taking into account the regional characteristics of the university. The main research methods are: 1.analysis and data processing of an array of theoretical sources and educational practice; 2. modeling of the phased implementation of an individual educational trajectory (hereinafter - IET), taking into account the regional characteristics of the university. The scientific novelty of the research: a personality-oriented model of education at the university was built, taking into account regional characteristics and factors affecting the formation of individual educational trajectories of students, namely, the content and organizational aspects of the IET implementation, taking into account the specifics of the northern region.

On the territory of Yakutia, a large number of national projects are being implemented related to the industrial development of the northern and arctic territories. A striking example is the construction of the Power of Siberia gas pipeline. When implementing investment projects, employers actively use the rotational work method, attracting specialists from the constituent entities of the Russian Federation and countries of the Near Abroad. Thus, the situation on the regional labor market may be characterized as highly competitive for the labor force from among the local population. In connection with the above, the positions of the authors of the study on training personnel for the regional labor market are as follows:

- to implement the best practices of student development, meeting their needs for early learning experience, and not just professional knowledge within the educational program. The labor market is the main factor in the design of the educational program, which inevitably leads to increased requirements for the teaching staff. Assessment of educational results should depend on the level of impact on science, economy and business and, ultimately, on the aggregate result for a particular region.

- a clear understanding and awareness of the paradigm of educational change by the teaching staff. The teaching load of a modern teacher often does not reflect the real needs of education, it is required to rebuild the system for assessing the efficiency of the teacher. He should not just broadcast knowledge that may be found in various messengers, but to a greater extent perform the function of $3 \mathrm{C}$ : communicate, coordinate and consult in the educational space.

- to develop a system of on-line training designed to optimize the work of the teaching staff in terms of the transfer of theoretical (knowledge) content. It is advisable to direct the freed up time to project work with students, discussion and study of theoretical issues in an applied way as objective mechanisms for checking the formation of 
competencies.

- to support the ideas of convergence of education. A modern employer is in demand for a specialist with competencies at the junctions of different areas of training, moving away from work in narrow specializations to cross-functional programs.

- actively interact with partner organizations: corporations, technology parks, development institutions, professional associations of the region. Close cooperation will allow educational organizations and businesses to cooperate in order to obtain maximum synergy: opening network programs for business needs, creating basic departments at enterprises, venture funds or funding by a university. The core will be the project track, in which students go from idea to prototype.

\section{Results and discussion}

In 2020, the global educational space faced great challenges. Many educational organizations have shifted the vector to the development and strengthening of those solutions that allow each specific person to realize themselves, build a trajectory of their development and be in demand in the new reality. Universities began to actively advocate for a personnel training system that meets the real challenges of the time, corresponds to the trends of the future and is aimed at developing the personality of a person who is able not to get confused in new conditions and is ready to evolve throughout his life, using training for further self-development and presentation of his competencies in labor market [8]. Thus, in order to quickly adapt to changes in the external environment, to approach the achievement of the set goals in a different way, it is required to organize work in terms of interaction between key participants within the educational organization. New challenges are making their demands on education: 1. easy access to information (presence of hyperlinks, links to interesting points); 2. autonomy (the ability to watch educational content at any, and most importantly - a short time); 3. individual training, taking into account the specifics of each person (personal routing); 4. relevance (understanding of the need to acquire competencies); 5. the ability to use all channels of information perception (auditory, visual, tactile).

The modernization of any educational organization begins with the transformation of its members. One of the factors complicating the renewal process is resistance to change on the ground. It is important to understand that the achievements of students, their academic performance and success in the labor market are more important than the formation of official documents. Currently, specialized departments are discussing new approaches to the accreditation of universities, where experts propose a transition from documentary audits to a system for assessing the quality of student training. From these positions, we propose, when developing an IET, to focus on an integrated approach, starting with the strategy and choosing the direction of the organization, analyzing the economic effect of implementation. In the traditional, classical understanding of education, work with a student group takes place within the framework of a tunnel program. As part of our research, we propose to consider IET as a tool for creating personality-oriented content that takes into account the abilities, desires, needs of the student himself, his long-term plans for his professional future, as well as trends and tendencies of the regional labor market (Figure $1)$. 


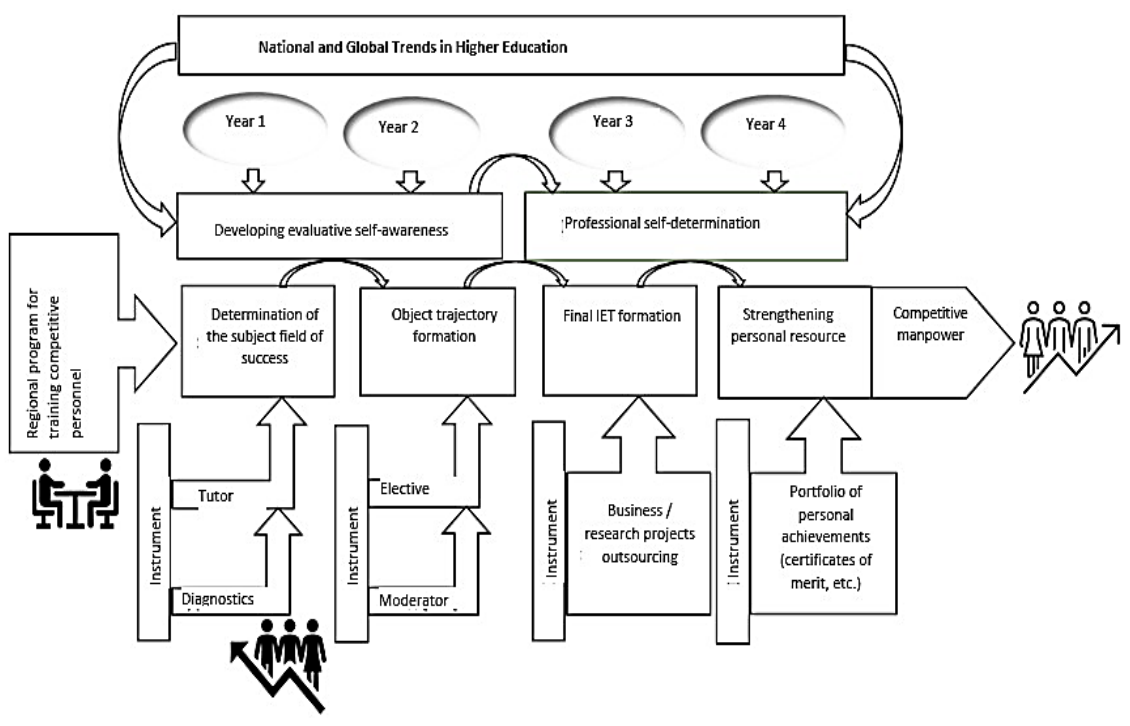

Fig. 1. Personality-oriented model of building IET.

In the course of modeling, we consider several course elements in the educational process:

- 1st year - a coworking course, within which students develop universal competencies: communication and interaction, search and analysis of information, argumentation of their own ideas and opinions, taking responsibility for their decisions. In the first year, students undergo diagnostics to determine the personal field of success, the tutor provides support and assistance in building the route of individual educational technology. Students are offered interdisciplinary projects with subsequent generation of their ideas.

- 2nd year - a reference course, where work in teams pursuant to several models is practiced.

Model number 1: students work under the guidance of moderators in the form of departments and/or industrial partners who offer the topics of design work that are in demand in the real sector of the economy.

Model number 2: students come up with an idea themselves, independently forming teams and working in a collaboration format.

In the support space, students are offered a set of elective disciplines (modules), including online courses of various digital educational platforms, whose task is to determine and concretize the chosen direction of training, by increasing their competitive advantages.

- 3rd year - a specialized course, students are divided into anthroflows in the chosen areas of training. A significant role at this stage is assigned to the project office of the educational organization, which is involved in providing the freedom to choose the schedule of the educational process. The base departments, together with employers, work on real and promising projects from the sector of science and economics. A student's education is no longer limited by the framework of the educational content of one university, but has endless opportunities and resources for its development due to integration into the global educational space.

- 4th course - a professional course allows the student to strengthen his personal potential, integrate into the professional community through his entrepreneurial projects and/or research work, participating in workshops, business conferences, educational 
forums, etc.

According to the model, regional employers play a significant role. We propose to implement orientation with self-determination of students in two versions: targeted training for determined applicants, for undecided - through diagnostics and tutoring. Moreover, if the order comes from the region/employer, then they act as customers of the graduate's competence model for their specific needs. Business project outsourcing assumes that regional employers offer students to solve professional problems in order to reduce their own costs while simultaneously searching for non-standard, creative approaches. As part of the work of the basic departments, employers may also act as moderators of students in their business projects.

The proposed educational model gives us the opportunity, without violating the requirements of federal state educational standards, to change not only the focus, but also the direction of training to meet the needs of the student and the labor market. Under the conditions of certain limitations, we consider it required to use the capabilities of the Federal State Educational Standard of Higher Education $3++$, which it hides, allowing the head of the educational program to build its logistics and the trajectory of student learning within it in a variety of ways.

\section{Conclusions}

Individual educational trajectories are the response of regional universities to global challenges in education. Regional employers play an important role and are a decisive factor influencing the organization and content of the educational process in higher education. For the implementation of IET in practice, first of all, a collective understanding is needed within a specific, separately taken university: starting from the leadership of the educational organization and ending with the teaching and auxiliary personnel of the departments. The educational organization must independently and collectively make a decision on the transition to IET.

The regulatory framework of federal and local documents should give more freedom to universities. The executive authorities need to make changes to the Federal State Educational Standard of Higher Education that will allow universities to effectively perform educational activities and not be afraid of inspections by control and supervisory bodies. The revision of the financial model of the dependence of universities on the student population requires special attention. When implementing an individual educational trajectory, the main place is given to the university student, his needs and motivation to build his personalized route, taking into account the demand for acquired competencies in the competitive labor market. The faculty is required not only to be ready, but also to be able to work in a digital and creative environment.

\section{References}

1. I. G. Zakharova, Education and science-education andes scene, 84 (2020)

2. K. Bullock, I. Jamieson, Educational studies, 307 (1995)

3. K. Bullock, A. Harris, I. Jamieson, Educational research, 21 (1996)

4. M. A. Volman, Teacher and teacher education, 15 (2005)

5. G. M. Parnikova, The concept of development of educational independence of students when training in a foreign language in a regional and ethnic context (not language higher education institution), 357 (2018)

6. E. A. Arkhangelskaya, S. G. Antsupova, Engineering education, 110 (2012) 
7. G. M. Parnikova, F. S. Androsova, S. G. Antsupova, World of science, culture, education, 82 (2018)

8. A. A. Verbitsky, The higher education today, 6 (2017) 